\title{
KẾT CÂUU CÂU MANG BỔ NGŨ THỜI LƯợNG TIẾNG HÁN (ĐỐI CHIẾU VỚI CÁCH BIỂU ĐẠT TƯƠNG ĐƯƠNG TRONG TIẾNG VIẸT)
}

\author{
Nguyễn Thị Hường* \\ Khoa Ngoại ngũu, Trường Đại học Su phạm Kỹ thuật Hưng Yên, \\ 189 Nguyễn Luơng Bằng, Phường Tân Bình, Hải Dương, Việt Nam \\ Nhận bài ngày 16 tháng 10 năm 2017 \\ Chỉnh sửa ngày 25 tháng 01 năm 2018; Chấp nhận đăng ngày 31 tháng 01 năm 2018
}

Tóm tắt: Bổ ngữ là một trong những thành phần chính trong câu tiếng Hán. Bổ ngữ tiếng Hán nói chung và bổ ngữ thời lượng tiếng Hán nói riêng có tần suất sử dụng rất cao. Trong khuôn khổ của bài viết này, chúng tôi chỉ tập trung bàn về trật tự kết cấu câu mang bổ ngữ thời lượng tiếng Hán, đồng thời tiến hành so sánh đối chiếu với trật tự kết cấu câu có cách biểu đạt tương đương trong tiếng Việt.

Tù khóa: kết cấu câu, bổ ngữ thời lượng, tiếng Hán, đối chiếu, tiếng Việt

\section{Lời mở đầu}

Tiếng Hán và tiếng Việt là hai ngôn ngữ cùng thuộc loại hình ngôn ngữ đơn lập, biện pháp chủ yếu để biểu thị quan hệ ngữ pháp và ý nghĩa ngữ pháp là dựa vào sự sắp xếp trật tự từ và hư từ trong câu, khi trật tự sắp đặt các từ thay đổi thì ý nghĩa của câu cũng thay đổi. Tùy thuộc vào từng loại hình tân ngữ, loại động từ và các ý nghĩa biểu đạt của bổ ngữ thời lượng mà mô hình kết cấu câu mang bổ ngữ thời lượng (dưới đây có chỗ viết tắt là BNTL) tiếng Hán là khác nhau. Điều này tạo nên tính phức tạp trong cách sử dụng BNTL cũng như cấu trúc câu mang BNTL tiếng Hán. Các nghiên cứu có liên quan về phạm trù bổ ngữ thời lượng tiếng Hán chủ yếu tập trung vào việc nghiên cứu bản thể về bổ ngữ thời lượng và là của các tác giả ở nước ngoài như: 间娇莲 (2007), 陈小红 (2002), 杨 峥琳-刘倩 (2006), 李大忠 (1996), 秦洪武 (2002), 匡鹏飞 (2013), 储泽祥 (2005), 曾妍 (2014), 车慧-张璐 (2016)... Hiện nay, chưa có nghiên cứu nào đi sâu vào việc so sánh đối chiếu BNTL tiếng Hán với tiếng Việt. Trong quá trình nghiên cứu, chúng tôi chủ yếu sử dụng các

* ĐT.: 84-983597810

Email: nguyenhuong.utehy09@gmail.com phương pháp: khảo sát, phân tích và so sánh đối chiếu. Thông qua việc phân tích và đối chiếu, chúng tôi chỉ ra điểm tương đồng, điểm khác biệt về trật tự kết cấu câu mang bổ ngữ thời lượng tiếng Hán với các cách biểu đạt tương đương trong tiếng Việt. Chúng tôi hy vọng đây sẽ là tài liệu giúp ích cho việc dạy và học tiếng Hán nói chung và bổ ngữ thời lượng tiếng Hán nói riêng. Nguồn dữ liệu được trích dẫn trong bài chủ yếu lấy từ các tác phẩm: "Chí Phèo" của Nam Cao, "Sống mòn" của Nam Cao, "Nhũng bàn tay đẹp ấy" của nhà văn Nam Cao, "Chiếc lược ngà" của Nguyễn Quang Sáng, 《奔跑的蜗牛》của tác giả蝶之灵 (“Ốc sên chạy” dịch giả Trần Thu), 《哇》 của tác giả 莫言 (“Éch” dịch giả Nguyên Trần), 《丰乳肥臀》 của tác giả莫言 (“Báu vật của đời" dịch giả Trần Đình Hiến), 《那些年我们一起追的女孩》 của tác giả九 把刀 (“Cô gái chúng ta tùng theo đuổi năm nào" dịch giả Lục Hương) và một vài ví dụ không chỉ ra nguồn trích dẫn cụ thể là của chúng tôi.

\section{2. Đối chiếu trật tự kết cấu câu mang BNTL tiếng Hán với các cách biểu đạt tương đương trong tiếng Việt}

Về thành phần bổ ngữ tiếng Việt, hiện nay vẫn còn những quan điểm khác nhau về các phạm trù có liên quan đến bổ ngữ như: phân 
loại bổ ngữ, tên gọi của các loại bổ ngữ hay vấn đề bổ ngữ là thành phần chính hay là thành phần phụ của câu... Trong đó, chúng tôi thấy rằng Diệp Quang Ban là tác giả có nhiều nghiên cứu về thành phần bổ ngữ tiếng Việt một cách chi tiết và cụ thể hơn cả. Các nghiên cứu thuộc lĩnh vực này của Diệp Quang Ban tiêu biểu có thể kể đến như: "Ngữ pháp Việt Nam phần câu" (2004), "Giáo trình ngữ pháp tiếng Việt, phần 2" (2008) và "Ngữ pháp Việt Nam” (2010)...

Trong "Ngữ pháp Việt Nam phần câu" (2004), tác giả cho rằng thực thể chịu tác động của hành động ở vị tố và đứng sau động từ chuyển tác gọi là tân ngữ (còn gọi là bổ ngữ trực tiếp). Yếu tố chỉ thực thể nhận vật trao do nghĩa của động từ ấn định và nó đứng sau động từ chuyển tác gọi là tân ngữ gián tiếp (cũng có thể gọi là bổ ngữ gián tiếp). Còn những yếu tố khác đứng sau vị tố cũng do ý nghĩa của vị tố ấn định nhưng theo quan hệ không chuyển tác thì gọi chung là bổ ngữ. Ở "Giáo trình ngữ pháp tiếng Việt, phần 2" (2008), tác giả cho rằng bổ ngữ tiếng Việt là thành phần phụ và trong phần lớn trường hợp có quan hệ với động từ, tính từ, vì vậy bổ ngữ là thành phần phụ của từ trong câu. Bổ ngữ trong tiếng Việt thường đứng sau động từ, tính từ; đôi khi nó cũng được đặt trước động từ, tính từ một cách có điều kiện như bổ ngữ chỉ cách thức được cấu tạo bởi các từ tượng thanh, tượng hình thì vị trí của nó có thể đứng trước hoặc sau động từ trung tâm. Ví dụ: Cô ây chỉ khúc khích cười/Cô ấy chỉ cười khúc khich (Ngô Tất Tố). Một cách khái quát, có thể phân biệt ba loại bổ ngữ sau đây:

- Bổ ngũ̃ trực tiếp (còn được gọi với tên khác là tân ngữ trực tiếp): bổ ngữ - thể đối tượng:

+ Cậu bé đào đất. (vật chịu tác động)

+ Cậu bé đào khoai. (vật cần đạt đến)

+ Cậu bé đào mương. (vật được hình thành)

+ Gió đẩy cánh cưa . (vật chịu tác động)

- Bổ ngữ gián tiếp (còn gọi là tân ngữ gián tiếp): bổ ngữ - thể tiếp nhận và bổ ngữ thuộc tính:

+ Ông Giáp tặng ông At một chiếc xe đạp thể thao. (thể tiếp nhận)
+ Cậu bé đưa tờ báo cho tôi. (thể tiếp nhận)

+ Tôi gọi ông ấy bằng bác. (thuộc tính)

+ Họ cử ông ấy làm giám đốc. (thuộc tính)

+ Chính phủ tặng bà cu ấy danh hiệu "Bà mẹ Việt Nam anh hùng”. (thể tiếp nhận)

- Bổ ngữ cảnh huống (còn gọi là trạng ngữ của từ để phân biệt với trạng ngữ của câu)

+ Họ học ở đại học bốn năm. (cảnh huống: thời gian (thời hạn))

+ Họ vừa đến đây hôm qua. (cảnh huống: thời gian (thời điểm))

+ Họ đang chơi cờ ngoài vuờn. (cảnh huống vị trí)

+ Xe này đi Vinh. (thể đích đến)

+ Cô Lụa đi chợ. (thể đích đến)

+ Con mèo tha chuột vào bếp. (cảnh huống: hướng)

+ Ông ấy đi Pháp qua đuờng Thái Lan. (Pháp: thể hướng; đường Thái Lan:cảnh huống:đường đi)

+ Giáp đi chơi rất thuờng xuyên. (cảnh huống: thời gian (tần số))

+ Dần đi bơi mỗi tuần một lần. (cảnh huống: thời gian (tần số))

+ Nó chép bài cho Giáp. (thể được lợi)

+ Mẹ rửa chân cho con. (thể được lợi)

+ Cậu bé đi chơi với tôi. (thể liên đới)

+ Giáp mở cửa bằng chìa khóa riêng. (cảnh huống:phương tiện)

+ Giáp gửi thư qua một người bạn. (cảnh huống: phương tiện)

+ Xe chạy rất nhanh. (cảnh huống: cách thức)

+ Họ làm việc rất tốt. (cảnh huống: cách thức)

+ Mọi người trò chuyện rất vui vé. (cảnh huống: cách thức)

+ Con gà chết đói. (cảnh huống: nguyên nhân)

+ Giáp mua chiếc áo để tặng bạn. (cảnh huống: mục đích)

+ Cậu bé làm chiếc xe đạp đổ. (cảnh huống: kết quả)

+ Cậu bé làm đổ chiếc xe đạp. (cảnh huống: kết quả)

+ Tôi sẽ đến anh chơi nếu được. (cảnh huống: điều kiện) 
+ Nó vẫn đi học tuy còn mệt. (cảnh huống; nhượng bộ hay nghịch đối)

+ Cái bàn ấy gãy chân. (thể (trong) trạng thái)

+ Con mèo kia cụt đuôi. (thể (trong) trạng thái)

+ Cây này vàng lá. (thể (trong) trạng thái)

+ Giáp nói về cuộc hop lớp chiều mai. (hiện tượng)

+ Giáp rất sợ rắn. (nguyên nhân)

+ Giáp nói Giáp sẽ về quê. (hiện tượng)

+ Giáp sợ rắn cắn. (nguyên nhân)

Trong cuốn "Ngữ pháp Việt Nam" (2010), về nội dung bổ ngữ tiếng Việt, tuy có đề cập đến tên gọi và phân loại bổ ngữ nhưng tác giả đã giản lược đi nhiều loại bổ ngữ, trong đó có loại bổ ngữ cảnh huống chỉ thời hạn và có bổ sung thêm một số loại bổ ngữ khác. Cụ thể như sau:

- Tân ngữ (còn gọi là bổ ngữ trực tiếp).

+ Cậu bé đào đất. (vật chịu tác động)

+ Cậu bé đào khoai. (vật cần đạt đến)

+ Cậu bé đào muoong. (vật được hình thành)

+ Gió đẩy cánh cưa. (vật chịu tác động và dời chuyển)

+ Họ phá con mương cũ. (vật bị phá hủy)

- Tân ngữ gián tiếp (còn gọi là bổ ngữ gián tiếp).

+ Ông Tị tặng chiếc xe đạp cho ông Dần. (Giới từ "cho" bắt buộc)

+ Ông Tị tặng (cho) ông Dần chiếc xe đạp. (Giới từ “cho" không bắt buộc)

+ Chính phủ tặng bà cu ấy danh hiệu "Bà mẹ Việt Nam anh hùng".

- Bổ ngữ ngôn đích thể (bổ ngữ của động từ nói năng, không tính trường hợp câu chứa lời dẫn)

+ Tị nói về cuộc họp lóp chiều mai.

+ Tị trình bày vấn đề môi truờng.

Tị bảo tuần tới Tị đi Đà Lạt. (bổ ngữ là mệnh đề)

- Bổ ngữ hiện tượng (bổ ngữ của động từ cảm nghĩ)

+ Cậu bé hiểu việc đó.

+ Cậu bé sợ gián.
+ Cậu bé xem hai con dế chọi nhau. (bổ ngữ là mệnh đề)

- Bổ ngữ cảnh huống (phân biệt với gia ngữ)

+ Ông ấy đang ở ngoài vườn. (không gian: vị trí)

+ Cô Lụa đi chợ. (không gian: đích đến)

+ Xe này chạy Vinh. (không gian: đích đến)

+ Ngày Lao động quốc tế là Ngày 1-5.

- Bổ ngữ của chủ ngũ.

+ Người này là bác sĩ.

+ Người này là bác sỹ giỏi nhất vùng này.

+ Hôm nay là Chủ nhật. (Đồng thời là bổ ngữ cảnh huống thời gian)

- Bổ ngữ của tân ngũ̃.

+ Họ cử ông ấy làm giám đốc.

+ Tôi gọi ông ấy bằng bác.

- Bổ ngữ của bổ ngữ.

+ Trăng lên sáng núi đồi. ("núi đồi" là bổ ngữ của bổ ngữ "sáng")

Với các quan điểm về bổ ngữ tiếng Việt như trên, chúng tôi thấy rằng "Giáo trình ngữ pháp tiếng Việt" (2008) là tài liệu có đề cập trực tiếp đến loại bổ ngữ cảnh huống chỉ thời hạn do cụm từ chỉ thời đoạn đảm nhiệm và cách phân loại bổ ngữ thành ba loại: bổ ngũ trực tiếp, bổ ngữ gián tiếp và bổ ngữ cảnh huống là cách phân loại ngắn gọn, thống nhất hơn về tên gọi của thành phần bổ ngữ tiếng Việt, là cơ sở cho việc tiến hành so sánh đối chiếu mô hình kết cấu câu mang BNTL tiếng Hán với cách biểu đạt tương đương trong tiếng Việt. Theo đó, có thể thấy rằng thành phần bổ ngũ thời lượng tiếng Hán tuơng đuơng với loại bổ ngũ cảnh huống: thời gian (thời hạn) trong tiếng Việt và thành phần tân ngữ tiếng Hán tương đương với thành phần bổ ngữ trực tiếp hoặc bổ ngữ gián tiếp của tiếng Việt. Hai loại bổ ngữ này trong tiếng Hán và tiếng Việt đều do cụm từ chỉ thời đoạn đảm nhiệm và biểu thị khoảng thời gian kéo dài của hành vi động tác hoặc trạng thái.

2.1. Đối chiếu mô hình kết cấu câu mang BNTL tiếng Hán khi động tù không mang tân ngũ với tiếng Việt 
Bổ ngữ thời lượng tiếng Hán và bổ ngữ cảnh huống chỉ thời hạn tiếng Việt đều được đặt sau động từ. Dạng thức của câu là:

Tiếng Hán: $\mathrm{S}+\mathrm{V}+($ 了 $)+\mathrm{C}$ ( thời lượng) $+($ 了)

Tiếng Việt: S + ( đã ) + V + C (cảnh huống chỉ thời hạn) + (rồi)

Ví dụ:

(1)上官金童躺了两天, 脑子渐渐灵活 了, 娜塔莎的形象又时时刻刻地出现在眼 前... (《丰乳肥臀》)

Kim Đồng nằm hai ngày, đầu óc dần dà trở lại linh hoạt, hình ảnh Natasa lúc nào cũng đứng ngay trước mặt... (“Báu vật của đời”).

(2)那个女公安干部, 参加过捉获司马 库的行动, 她犹豫了一下, 果断地对看守 说: “给他开铐子。”... (《丰乳肥臀》)

Người cán bộ công an này đã từng tham gia vây bắt Tư Mã Khố. Chị do dụ một thoáng rồi bảo: - Mở còng cho anh ta!... (“Báu vật của đời”).

(3) 我等了一天, 他也不来.

(Tôi đã đọii cả một ngày, anh ấy cũng không đến.)

2.2. Đối chiếu mô hình kết cấu câu mang BNTL tiếng Hán khi động tù mang tân ngư hũu định với tiếng Việt

Khi đề cập đến trật tự kết cấu câu mang bổ ngữ thời lượng tiếng Hán, tác giả 李大忠 (1996) đã phân chia kết cấu câu thành các dạng thức khác nhau tùy thuộc vào từng loại tân ngữ khác nhau. Trong đó có nhóm tân ngữ hữu định và nhóm tân ngữ vô định, tác giả cho rằng nhóm tân ngữ hữu định là các tân ngữ xác định và rõ ràng, có tính chỉ định cao như: đại từ nhân xưng, tên người, hoặc tân ngữ có định ngữ cụ thể ... và nhóm tân ngữ vô định là các danh từ có chỉ định tính thấp, chỉ chung chung, không xác định. Vị trí của tân ngữ hữu định là được đặt trước bổ ngữ thời lượng, công thức cụ thể như sau:

Tiếng Hán: $\mathrm{S}+\mathrm{V}+($ 了 $)+\mathrm{O}$ (hữu định)+ $\mathrm{C}$ (thời lượng) $+($ 了)

Tiếng Việt: $\mathrm{S}+($ đã $)+\mathrm{V}+\mathrm{C}$ (trực tiếp/ gián tiếp) $+\mathrm{C}$ (cảnh huống chỉ thời hạn) + (rồi)

Ví dụ:

(4)我说: 小狮子是挺好, 但王肝 迷她十几年了, 我不能夺朋友所爱... (《哇》)

Tôi nói: “Tiểu sư tử rất tốt, nhưng Vương Can đã mê chị ấy mười mấy năm nay. Cháu không thể cướp người yêu của bạn... ("ÉEch").

(5)是啊你内敛, 你非常内敛的在分手 的时候把男朋友给揍了, 非常内敛的在卧 室里贴满了偶像刘德华的大头照, 非常内 敛的喜欢了周放好几年却根本不知道周放 是高咱几届的中文系师兄 $\quad \cdots$ （《奔跑的 蜗牛》)

Vâng, mày e dè. E dè đến nỗi khi chia tay còn tung cho bạn trai mấy cú đấm. E dè đến nỗi dán đầy ảnh Lưu Đức Hoa trong lòng. $\mathrm{E}$ dè ngưỡng mộ Chu Phóng mấy năm liền mà không biết anh ấy là sinh viên khoa văn học trên chúng ta mấy khóa... ("Ốc sên chạy").

Qua phân tích trên, có thể thấy rằng mô hình kết cấu câu mang BNTL khi động từ mang tân ngữ hữu định trong tiếng Hán và tiếng Việt là cơ bản tương đồng.

\section{3. Đối chiếu mô hình kết cấu câu mang} BNTL tiếng Hán khi động tù mang tân ngũ là tân ngũ vô định với tiếng Việt

Trong tiếng Hán, khi động từ mang tân ngữ là tân ngữ vô định tức danh từ không xác định, danh từ chỉ sự vật nói chung thì có hai cách sắp xếp câu: thứ nhất là đặt bổ ngữ thời lượng trước tân ngữ, giữa bổ ngữ thời lượng và tân ngữ có thể thêm trợ từ “的 ", hoặc là phải lặp lại động từ và bổ ngữ thời lượng đặt sau động từ nhắc lại. Đối với tân ngữ chỉ chung chung như trường hợp này của tiếng Hán thì tiếng Việt thường hay sử dụng cách đặt bổ ngữ cảnh huống chỉ thời hạn sau bổ ngũ trực tiếp / bổ ngữ gián tiếp nhiều hơn là cách đặt bổ ngữ cảnh huống chỉ thời hạn trước bổ ngữ trực tiếp / bổ ngữ gián tiếp nhưng tiếng Việt không có cách lặp lại động từ như trong tiếng Hán. Công thức cụ thể như sau: 
Tiếng Hán: $\mathrm{S}+\mathrm{V}+($ 了 $)+\mathrm{C}$ (thời lượng) + (的) $+\mathrm{O}$ (vô định) $+($ 了 $) / \mathrm{S}+\mathrm{V}+\mathrm{O}$ (vô định $)+\mathrm{V}+($ 了) $+\mathrm{C}$ (thời lượng) $+($ 了 $)$

Tiếng Việt: $\mathrm{S}+($ đã $)+\mathrm{V}+\mathrm{C}$ (trực tiếp/ gián tiếp) $+\mathrm{C}$ (cảnh huống chỉ thời hạn) + (rồi)

$\mathrm{S}+($ đã $)+\mathrm{V}+\mathrm{C}$ (cảnh huống chỉ thời hạn) $+\mathrm{C}$ (trực tiếp / gián tiếp) + (rồi)

Ví dụ:

(6)她学汉语学了两个多月了。（《汉语 教程》)

(Cô ấy đã học tiếng Hán hơn hai tháng rồi. / Cô ấy đã học hơn hai tháng tiếng Hán rồi.)

(7)我学了一年汉语了. (《汉语教程》)

(Tôi đã học tiếng Hán một năm rồi. / Tôi đã học một năm tiếng Hán rồi.)

(8)而我当了三年的学艺股长, 每次遇 到教室布置都是这些女生跟我通力完成... 1 《那些年我们一起追的女孩》).

Tôi còn làm trưởng nhóm phụ trách văn thể mỹ 3 năm liền, mỗi lần trang trí lớp đều cùng với mấy đứa con gái này hợp lực hoàn thành ...( "Cô gái chúng ta tùng theo đuổi năm nào").

(9)姑姑干这行干了五十多年, 直到现 在也没闲着 $\cdots$ (《哇》)

Bà cô ta làm công việc này hơn năm mươi năm, cho đến bây giờ vẫn chưa được nghỉ ngơi... ("Ếch").

(10) Tất cả đều lấy làm đau xót vì trình độ văn hóa quá thấp kém của mình và đang ráo riết học thêm. Cả đội, chỉ có một mình chị chính trị viên là đã học hai năm trung học... ("Nhũng bàn tay đẹp ấy")

Phân tích trên cho thấy rằng mô hình kết cấu câu mang BNTL khi động từ mang tân ngữ là tân ngữ vô định trong tiếng Hán và tiếng Việt vừa có cách sắp xếp tương đồng vừa có cách sắp xếp khác nhau.

2.4. Đối chiếu mô hình kết cấu câu mang BNTL tiếng Hán khi động tù là động tù li hợp mang ý nghĩa biểu thị hành động duy trì hoặc kéo dài lâu với tiếng Việt
Động từ ly hợp là loại động từ đặc biệt trong tiếng Hán và tiếng Việt không có. Khi đề cập đến đặc điểm kết cấu câu mang BNTL và động từ là động từ ly hợp, tác giả 杨峥琳, 刘倩 (2006) và tác giả 李大忠 (1996) cùng quan điểm khi phân chia động từ ly hợp thành hai nhóm: thứ nhất là những động từ biểu thị hành vi động tác hoặc trạng thái có tính duy trì cao, có thể biểu thị ý kéo dài trong khoảng thời gian lâu như: 游泳, 睡觉, 跑步, 洗 澡, 唱歌, 开会, 聊天, 散步, 谈话... và nhóm thứ hai là trường hợp động từ ly hợp biểu thị hành động xảy ra trong khoảng thời gian ngắn không thể duy trì hoặc kéo dài lâu hoặc chỉ diễn ra trong nháy mắt, tạo thành kết quả nào đó và bổ ngữ thời lượng lúc này biểu thị khoảng thời gian kéo dài của trạng thái từ khi có kết quả đến thời điểm nói, đó là các động từ: 毕业, 结婚, 握手, 辞职, 开业, 离婚... Với mỗi trường hợp động từ ly hợp như trên cấu trúc câu mang BNTL sẽ khác nhau. Khi động từ là động từ ly hợp biểu thị hành động duy trì hoặc kéo dài lâu thì có hai cách sắp xếp câu: hoặc là đặt bổ ngữ thời lượng vào giữa cụm động từ ly hợp hoặc là lặp lại động từ và BNTL đứng sau động từ lặp lại. Ví dụ:

(11) 你姑姑住了半个月院，伤没好利 索就从院里跑出来... (《哇》).

Cô con nằm viện mất nửa tháng, vết thương nhiễm trùng chưa kịp kéo da non đã chạy khỏi bệnh viện ...("Ếch").

(12) 他游泳游了一个下午. (《汉语教 程》)

(Anh ấy đã bơi cả một buổi chiều.)

Tiếng Việt cũng có các động từ song âm tiết tương đương với các động từ ly hợp như trên của tiếng Hán, tuy nhiên tiếng Việt không có cách sử dụng phân tách hai âm tiết ra với nhau như trong tiếng Hán. Các động từ song âm tiết này trong tiếng Việt cũng không có cách lặp lại động từ như trong tiếng Hán. Từ các ví dụ trên, có thể đưa ra mô hình cấu trúc câu mang $B N T L$ và động từ là động từ ly 
hợp biểu thị hành động duy trì hoặc kéo dài lâu trong tiếng Hán với cách biểu đạt tương đương trong tiếng Việt như sau:

Tiếng Hán: $\mathrm{S}+\mathrm{V}+($ 了 $)+\mathrm{C}$ (thời lượng) $+\mathrm{O}+($ 了 $) / \mathrm{S}+\mathrm{V}+\mathrm{O}+\mathrm{V}+($ 了 $)+\mathrm{C}$ (thời lượng) $+($ 了)

Tiếng Việt: $\mathrm{S}+($ đã $)+\mathrm{V}+\mathrm{C}$ (cảnh huống chỉ thời hạn) + (rồi) .

Qua phân tích trên, có thể thấy rằng mô hình kết cấu câu mang BNTL khi động từ là động từ li hợp mang ý nghĩa biểu thị hành động duy trì hoặc kéo dài lâu trong tiếng Hán và tiếng Việt là khác nhau.

2.5. Đối chiếu mô hình kết cấu câu mang BNTL tiếng Hán khi động tù̀ về mặt ý nghĩa không biểu thị động tác kéo dài, không biểu thị hành động mang tính duy trì lâu với tiếng Việt

Các động từ về mặt ý nghĩa không biểu thị động tác kéo dài, không biểu thị hành động mang tính duy trì lâu trong tiếng Hán gồm một số động từ ly hợp như: 毕业, 结婚, 起 床, 开业, 离婚, 下 (课) ... hay các động từ như: 到, 来, 去, 回来, 回去, 死, 离 开... Dạng thức câu tiếng Hán và tiếng Việt trong trường hợp này có thể khái quát theo công thức sau: $+了$

Tiếng Hán: $\mathrm{S}+\mathrm{V}+(\mathrm{O})+\mathrm{C}$ (thời lượng)

Tiếng Việt: $\mathrm{S}+($ đã $)+\mathrm{V}+\mathrm{C}$ (trực tiếp / gián tiếp) $+\mathrm{C}$ (cảnh huống chỉ thời hạn) + rồi

Ví dụ:

(13) 高梦九: (对蝌蚪、小狮子) 你们两 位, 是合法夫妻吗?

蝌蚪: 结婚三十多年了。(《哇》)

Cao Mộng Cửu (Nhìn Khoa Đẩu và "Tiểu sư tử”). Nhị vị có phải là vợ chồng hợp pháp không?

Khoa Đẩu: Chúng tôi cưới nhau đã ba mươi năm. ("Ếch").

(14) 他毕业三年半了.(《现代汉语实用 语法分析 -上册》).

(Anh ấy tốt nghiệp ba năm rưỡi rồi.)

(15) 他来中国半年了. (“Ngũ pháp tiếng Hoa").
(Anh ấy đến Trung Quốc nửa năm rồi.)

(16) 我去叫他的时候, 他已经起床半 个小时了. (“Ngũu pháp tiếng Hoa").

(Lúc mà tôi đi gọi anh ấy thì anh ấy đã dạy nửa tiếng rồi.)

（17）她父母离婚多年，一直跟妈妈一 起生活, 她妈妈去年又诊断出乳腺癌...

(《奔跑的蜗牛》)

Bố mẹ cô ấy li dị đã lâu, cô ấy sống cùng mẹ. Năm ngoái mẹ cô ấy bị chẩn đoán mắc bệnh ung thư vú ... ("Ốc sên chạy").

Từ sự phân tích như trên, có thể thấy rằng mô hình kết cấu câu mang BNTL khi động từ về mặt ý nghĩa không biểu thị động tác kéo dài, không biểu thị hành động mang tính duy trì lâu ( bao gồm một số động từ ly hợp nhu: 毕业, 结婚, 起床, 开业, 离婚, 下 (课) $\cdots$ hay các động từ như: 到, 来, 去, 回来, 回去, 死, 离开... trong tiếng Hán và tiếng Việt là tương đồng.

2.6. Đối chiếu mô hình kết cấu câu mang BNTL và có phó tù trong tiếng Hán với cách biểu đạt tương đương trong tiếng Việt

2.6.1. Đối chiếu mô hình kết cấu câu mang BNTL có phó tù ở dạng khẳng định trong tiếng Hán với cách biểu đạt tuoong đương trong tiếng Việt

Đề cập đến vị trí của phó từ trong câu mang BNTL tiếng Hán, tác giả 刘月华 (2001) cho rằng các phó từ như: “已经”, “才”, “整 整” .v.v... thường được đặt trước động từ, ngoài ra các phó từ này cũng có thể đặt trước BNTL và hai cách sắp xếp trật tự kết cấu câu này đều biểu thị khoảng thời gian kéo dài của hành vi động tác hoặc của trạng thái nào đó. Theo đó, trong các ví dụ dưới đây tác giả 刘 月华 đều đưa ra hai cách sắp xếp câu như sau:

(18) 小马已经等你一个小时了./ 小马 等你已经一个小时了.

(Tiểu Mã đã đợi bạn một tiếng rồi. / Tiểu Mã đợi bạn đã một tiếng rồi.)

(19) 我们才走了半个小时你就累了? / 我们走了才半个小时你就累了 
(Chúng ta mới đi nửa tiếng mà bạn đã mệt rồi sao? / Chúng ta đi mới nửa tiếng mà bạn đã mệt rồi sao?)

(20) 我整整学了三年中文. / 我学中文 整整三年了.

(Tôi vừa vặn / vừa đúng đã học ba năm tiếng Trung. / Tôi vừa vặn / vừa đúng đã học tiếng Trung ba năm./ Tôi đã học tiếng Trung tròn ba năm. / Tôi đã học tròn ba năm tiếng Trung.)

(21) 我们今年上了将近二百天 (的) 课.

(Năm nay chúng tôi đã đi học gần hai trăm ngày.)

Có thể thấy rằng, ở hai ví dụ (18) và (19) thì vị trí của phó từ “已经” và phó từ “才” trong tiếng Hán là giống với phó từ “ đã” và “ mới” trong tiếng Việt đó là đứng trước động từ hoặc trước BNTL hay bổ ngữ cảnh huống thời hạn. Ngoài ra, các phó từ này trong tiếng Hán và tiếng Việt đều không thể đứng cuối câu. Tiếng Hán và tiếng Việt không tồn tại các cách sau:

* 我们走了半个小时才你就累了/小马 等你一个小时了已经.

* Chúng ta đi nửa tiếng mói mà bạn đã mệt rồi sao? / Tiểu Mã đợi bạn một tiếng rồi đã.

Ở ví dụ (20), Theo Phan Văn Các cùng nhóm tác giả (2006) thì phó từ “整整” trong tiếng Hán có nghĩa là "tròn” hoặc "trọn” trong tiếng Việt. Tuy nhiên, ở góc độ từ loại của từ "tròn" hay "trọn" trong tiếng Việt theo Hoàng Phê cùng nhóm tác giả (2014) thì "tròn" hay "trọn" không phải là phó từ mà là tính từ. Từ "tròn" hoặc "trọn" có thể đứng trước cụm từ "ba năm" nhưng lại không phù hợp khi đặt tính từ "tròn" hoặc "trọn" trước động từ "học", tiếng Việt không tồn tại cách sắp xếp là: Tôi đã trọn hoc ba năm tiếng Trung. / Tôi đã tròn hoc ba năm tiếng Trung hay Tôi đã trọn học tiếng Trung ba năm./Tôi đã tròn học tiếng Trung $b a$ năm. Vì vậy, trường hợp này nên dùng tính từ "vừa vặn" hay "vừa đúng" thì câu văn sẽ trở nên hoàn chỉnh hơn. Ví dụ (21) có phó từ “将 近và động từ ly hợp “上课”, mặc dù tác giả 刘月华 mới chỉ đưa ra một cách đặt cụm "phó từ và BNTL: 将近 + 二百天” vào giữa cụm động từ ly hợp nhưng như đã đề cập ở trên đối với động từ ly hợp biểu thị hành động có thể kéo dài, duy trì lâu thì thực tế câu này còn có thể có cách lặp lại động từ là: 我们今年上 课上了将近二百天”. Từ đó có thể thấy rằng, tùy thuộc vào từng phó từ và loại hình tân ngữ cụ thể được sử dụng trong câu mà mô hình kết cấu câu mang BNTL tiếng Hán và có phó từ ở dạng khẳng định vừa có thể có cách sắp xếp giống, vừa có cách sắp xếp khác so với cách biểu đạt tương đương trong tiếng Việt. Dạng thức của câu tiếng Hán và tiếng Việt trong trường hợp này như sau:

\section{Mô hình 1:}

Tiếng Hán: $\mathrm{S}+$ phó từ $+\mathrm{V}+($ 了 $)+(\mathrm{O})+$ $\mathrm{C}$ (thời lượng $)+($ 了 $) / \mathrm{S}+$ phó từ $+\mathrm{V}+($ 了 $)+$ $\mathrm{C}$ (thời lượng) $+(\mathrm{O})+($ 了 $)$

Tiếng Việt : $\mathrm{S}+$ phó từ / tính từ $+\mathrm{V}+\mathrm{C}$ (cảnh huống thời hạn $)+(\mathrm{C}$ (trực tiếp) / (gián tiếp $))+($ rồi $) / \mathrm{S}+$ phó từ / tính từ $+\mathrm{V}+(\mathrm{C}$ (trực tiếp) /(gián tiếp)) $+\mathrm{C}$ (cảnh huống thời hạn) + (rồi).

\section{Mô hình 2:}

Tiếng Hán: $\mathrm{S}+\mathrm{V}+(\mathrm{O})+$ phó từ $+\mathrm{C}$ (thời lượng $)+($ 了 $) . / \mathrm{S}+$ dộng từ $+($ 了 $)+$ phó từ $+\mathrm{C}$ (thời lượng) $+($ 的 $)+(\mathrm{O}$ của động từ ly hợp) + (了). / $\mathrm{S}+\mathrm{V}+(\mathrm{O}$ của động từ ly hợp) $+\mathrm{V}+($ 了 $)+$ phó từ $+\mathrm{C}$ (thời lượng) $+($ 了 $)$.

Tiếng Việt : $\mathrm{S}+\mathrm{V}+(\mathrm{C}$ (trực tiếp) / (gián tiếp) $)+$ phó từ $/$ tính từ $+\mathrm{C}$ (cảnh huống thời hạn $)+($ rồi). $/ \mathrm{S}+\mathrm{V}+$ tính từ $+\mathrm{C}$ (cảnh huống thời hạn $)+\mathrm{C}$ (trực tiếp) / (gián tiếp) + ( rồi).

Ở mô hình thứ nhất, do đặc trưng ngữ pháp của phó từ trong tiếng Hán và tiếng Việt đều thường hay đứng trước động từ hoặc tính từ để bổ sung ý nghĩa cho động từ hoặc tính từ. Cho nên phạm vi và đối tượng chính mà phó từ tu sức trong trường hợp này là động từ không phải là BNTL hay bổ ngữ cảnh huống thời hạn. Vì vậy, mô hình thứ nhất này thường mang ý nghĩa biểu thị khoảng thời gian kéo 
dài của hành vi động tác hoặc của trạng thái từ khi bắt đầu hoặc kết thúc đến thời điểm nói một cách khách quan hơn là bao hàm ý đánh giá chủ quan về khoảng thời gian nhất định nào đó là ngắn hay dài, nhiều hay ít.

Với mô hình thứ hai thì phó từ đứng trước BNTL tiếng Hán hoặc bổ ngữ cảnh huống thời hạn tiếng Việt, vì vậy đối tượng trực tiếp được phó từ tu sức chính là bổ ngữ thời lượng hoặc bổ ngữ cảnh huống thời hạn không phải là động từ. Do vậy, câu có thể bao hàm ý đánh giá chủ quan của chủ thể phát ngôn về khoảng thời gian kéo dài của hành vi động tác hoặc của trạng thái từ khi bắt đầu hoặc hoàn thành đến thời điểm nói là dài hay ngắn, nhiều hay ít hoặc chỉ biểu thị khoảng thời gian kéo dài của hành vi động tác nào đó theo như thực tế khách quan không mang ý đánh giá chủ quan. Tùy thuộc vào ngữ cảnh cụ thể, dựa vào ý của câu văn phía trước và sau đó, tùy thuộc vào tính chất biểu thị lượng thời gian của cụm từ chỉ thời đoạn làm BNTL hoặc bổ ngữ cảnh huống thời hạn được sử dụng trong câu mà câu có thể biểu thị ý khách quan hoặc đánh giá chủ quan.

Phân tích trên cho thấy mô hình kết cấu câu mang BNTL và có phó từ ở dạng khẳng định trong tiếng Hán vừa có điểm tương đồng vừa có sự khác biệt so với cách biểu đạt tương đương trong tiếng Việt.

\subsection{2. Đối chiếu mô hình kết cấu câu} mang BNTL có phó tù phủ định trong tiếng Hán với các cách biểu đạt tuơng đương trong tiếng Việt

Tác giả 吕叔湘 (1992) cho rằng nếu cụm từ chỉ thời đoạn được đảo lên trước cụm động từ theo dạng thức: chủ ngữ + cụm từ chỉ thời đoạn + 没 + động từ + tân ngữ + 了 thì cụm từ chỉ thời đoạn trong trường hợp này đóng vai trò là thành phần trạng ngữ không phải là bổ ngữ, ý nghĩa của câu là dùng để phủ định hành vi động tác không xảy ra từ một khoảng thởi gian trước đó và duy trì đến thời điểm nói. Trong khuôn khổ nội dung của bài viết này, chúng tôi không đi sâu vào phân tích dạng thức câu có cụm từ chỉ thời đoạn làm trạng ngữ mà chúng tôi chỉ tập trung đi vào phân tích và đối chiếu mô hình kết cấu câu mang cụm từ chỉ thời đoạn đứng sau động từ làm bổ ngữ thời lượng và có phó từ phủ định với cách biểu đạt tương đương trong tiếng Việt.

Tác giả匡鹏飞 (2013) và tác giả 刘月华 (2001) cùng đồng quan điểm rằng: các phó từ phủ định như: “没”, “没有” hoặc “不” có thể đứng trước động từ hoặc đứng trước BNTL trong câu mang BNTL. Ví dụ:

(22)他们没认识几天就结婚了. (《实用 现代汉语语法》)

(Họ chưa/ chẳng/không quen biết được mấy ngày đã kết hôn rồi.)

(23)小明中学毕业没几天, 别听他吹 牛. (《实用现代汉语语法》)

(Tiểu Minh tốt nghiệp trung học chưa được mấy ngày, đừng nghe anh ấy nói khoác.)

(24)他没学几个月英语就说得很好了. / 他学没几个月英语就说得很好了.

(Anh ấy chưa học tiếng Anh được mấy tháng đã nói rất tốt rồi. /Anh ấy học chưa được mấy tháng tiếng Anh đã nói rất tốt rồi./ Anh ấy học tiếng Anh chưa được mấy tháng đã nói rất tốt rồi.)

Các phó từ phủ định “没”, “没有”, “ 不” trong tiếng Hán và "chưa", "chẳng" hay "không" trong tiếng Việt đều giống nhau về vị trí hoặc là đứng trước động từ hoặc là đứng trước bổ ngữ thời lượng tiếng Hán và bổ ngũ̃ cảnh huống thời hạn tiếng Việt, đồng thời phó từ phủ định không đứng cuối câu trong trường hợp câu mang ý phủ định thuần túy.

Vì vậy, mô hình kết cấu câu mang BNTL và có phó từ phủ định khi không có tân ngữ trong tiếng Hán với các cách biểu đạt tương đương trong tiếng Việt là tương đồng. Khi trong câu có tân ngữ thì tùy thuộc vào loại hình tân ngữ trong câu mà mô hình cấu trúc câu của tiếng Hán có thể có cách sắp xếp giống hoặc khác so với cách biểu đạt tương đương trong 
tiếng Việt. Công thức cụ thể như sau:

Tiếng Hán: $\mathrm{S}+(\mathrm{O}$ của động từ ly hợp $)+$ $\mathrm{V}+$ phó từ phủ định $+\mathrm{C}$ (thời lượng) + (thành phần khác). $/ \mathrm{S}+$ phó từ phủ định $+\mathrm{V}+\mathrm{C}$ (thời lượng) $+(\mathrm{O})+$ (thành phần khác). $/ \mathrm{S}+$ $\mathrm{V}+$ phó từ phủ định $+\mathrm{C}$ (thời lượng $)+(\mathrm{O})+$ (thành phần khác).

Tiếng Việt: $\mathrm{S}+$ phó từ phủ định $+\mathrm{V}+(\mathrm{C}$ (trực tiếp) / (gián tiếp) $)+\mathrm{C}$ (cảnh huống thời hạn $)+$ (thành phần khác). $/ \mathrm{S}+\mathrm{V}+$ phó từ phủ định $+\mathrm{C}$ (cảnh huống thời hạn $)+(\mathrm{C}$ (trực tiếp) / (gián tiếp) $)+($ thành phần khác). $/ \mathrm{S}+\mathrm{V}$ $+\mathrm{C}$ (trực tiếp) / (gián tiếp) + phó từ phủ định + $\mathrm{C}$ (cảnh huống thời hạn) + (thành phần khác)

- Mô hình cấu trúc câu mang bổ ngữ thời lượng tiếng Hán hoặc bổ ngữ cảnh huống thời hạn tiếng Việt có phó từ phủ định trong hai trường hợp phó từ phủ định đứng trước động từ hoặc đứng trước BNTL, bổ ngữ cảnh huống thời hạn tiếng Việt có một số ý nghĩa biểu đạt sau đây:

+ Phó từ phủ định trong tiếng Hán và tiếng Việt đều chủ yếu đứng trước động từ hoặc tính từ, phạm vi tu sức và đối tượng trực tiếp, gần nhất của phó từ phủ định trong trường hợp này là động từ không phải là BNTL hay bổ ngữ cảnh huống thời hạn. Vì vậy, khi phó từ phủ định đứng trước động từ thì thường dùng để phủ định, biểu thị sự phản bác hay không đồng ý với ý kiến của người khác. Đặc điểm của cụm từ chỉ thời đoạn trong trường hợp này thường là cụm từ chỉ khoảng thời gian cụ thể như: hai ngày, ba năm, sáu tháng v.v... Ví dụ:

(25) 他没有学习两年, 他学了一年.

(Anh ấy không phải đã học hai năm mà là anh ấy đã học một năm.)

Trong câu này phó từ phủ định “没有” đứng trước động từ “学习” và ý nghĩa của câu trong tiếng Hán và tiếng Việt đều biểu thị phủ định khoảng thời gian học không phải là hai năm mà là một năm.

- Mô hình kết cấu câu mang BNTL tiếng Hán hoặc bổ ngữ cảnh huống thời hạn tiếng Việt khi phó từ phủ định đứng trước động từ còn có thể dùng để phủ định một cách hoàn toàn, bao hàm ý biểu thị hành vi động tác chưa từng xảy ra và chưa từng kéo dài một khoảng thời gian nào đó. Cụm từ chỉ thời đoạn trong mô hình kết cấu câu này thường chỉ khoảng thời gian rất ngắn với các đơn vị chỉ thời gian như: giây, phút v.v... Ví dụ:

(26) 在记者的追问下，一位领导人不 得不承认:“我们没有开过一分钟的会”（ 北京大学中国语言学研究中心CCL语料 库)

(Lúc bị phóng viên truy hỏi đến cùng, một lãnh đạo không thể không thừa nhận rằng: "Chúng tôi chưa hề hop một giây phút nào".)

- Đối với mô hình kết cấu câu mang BNTL tiếng Hán hoặc bổ ngữ cảnh huống thời hạn tiếng Việt khi phó từ phủ định được đặt trước cụm từ chỉ thời đoạn không đặt trước động từ nếu lược bỏ phó từ phủ định đi thì câu vẫn thành câu. Sự khác biệt về ý nghĩa nếu có khi dùng phó từ phủ định trước BNTL tiếng Hán hoặc bổ ngữ cảnh huống thời hạn tiếng Việt so với cách đặt phó từ phủ định trước động từ là: câu vừa có thể biểu thị khoảng thời gian kéo dài của hành vi động tác hoặc trạng thái từ khi bắt đầu hoặc kết thúc đến thời điểm nói không phải như cụm từ chỉ thời đoạn được sử dụng trong câu, ngoài ra câu còn có thể bao hàm ý đánh giá chủ quan về khoảng thời gian kéo dài của hành vi động tác hoặc của trạng thái từ khi bắt đầu đến khi kết thúc là rất ngắn, rất ít. Cụm từ chỉ thời đoạn trong trường hợp này thường là cụm từ chỉ khoảng thời gian ngắn, ít. Ví dụ:

（27）金枝进去没十分钟,沉着脸，气夯夯 地回来了.(北京大学中国语言学研究中心 CCL语料库)

(Kim Chi vào trong chưa được mười phút, mặt mày sa sầm, hùng hổ quay về rồi.)

(28) Chẳng qua là cô cũng có ý lường tôi, không thật lòng thật dạ với tôi. Cô không có bụng giở giáo thì hà cớ làm sao tôi mới về nhà chura đầy một tháng cô đã phải lấy ngay người khác?... ("Sống mòn")

Qua phân tích trên, có thể thấy rằng mô 
hình kết cấu câu mang BNTL có phó từ phủ định trong tiếng Hán và các cách biểu đạt tương đương trong tiếng Việt là vừa có đặc điểm tương đồng vừa có sự khác biệt.

2.7. Đối chiếu mô hình kết cấu câu mang BNTL biểu thị hành vi động tác thư hai được thực hiện sau khi hành vi động tác thư nhất bắt đầu hoạc kết thúc cách một khoảng thời gian nhất định nào đó trong tiếng Hán với cách biểu đạt tuơng đurong trong tiếng Việt

Trong tiếng Hán, tùy vào loại hình tân ngữ, loại động từ hay tùy thuộc vào từng ý nghĩa biểu đạt của BNTL mà có mô hình kết cấu câu mang BNTL ở các dạng thức khác nhau. BNTL tiếng Hán ngoài biểu thị ý nghĩa khoảng thời gian kéo dài hoặc duy trì của hành vi động tác hay của trạng thái nào đó, BNTL cũng biểu thị khoảng thời gian kéo dài của hành vi động tác hoặc của trạng thái từ khi bắt đầu hoặc hoàn thành đến thời điểm nói. Đồng thời, BNTL còn biểu thị ý nghĩa sau khi hành vi động tác thứ nhất bắt đầu hoặc kết thúc cách một khoảng thời gian nhất định nào đó thì tiến hành hành vi động tác thứ hai. Ví dụ:

(29) 大会开始不久他就发了言. （《实 用现代汉语语法》)

(Đại hội bắt đầu không lâu thì anh ấy phát biểu.)

(30) 你吃完饭半个小时再吃药. （《实 用现代汉语语法》)

(Bạn ăn cơm xong / ăn xong cơm nửa tiếng đồng hồ hãy/rồi hãy uống thuốc.)

(31) 我起床后十分钟开始听广播. (《实用现代汉语语法》)

(Sau khi thức dậy muời phút (thi) tôi bắt đầu nghe đài.)

(32) Lý Kiến nghĩ ngọi một lúc rồi bảo cứ về rồi ông liệu. Ông liệu nghĩa là ông che đậy cái án của hắn cho không ai biết và mỗi lần có trát về nhắc, ông lại khai rằng: vẫn chưa có tên Chức về... ("Chí Phèo")

(33) Tôi nghĩ thầm, con bé đang bị dồn vào thế bí, chắc nó phải gọi ba thôi. Nó nhìn dáo dác một lúc rồi kêu lên: Cơm sôi rồi, chắt nước giùm cái! ... (Chiếc lược ngà)

(34) Anh đi được một lúc thì tôi đến. (Tư điển tiếng Việt)

Từ các ví dụ trên, có thể thấy dạng thức của câu mang BNTL biểu thị sau khi hành vi động tác thứ nhất bắt đầu hoặc hoàn thành cách một khoảng thời gian nhất định nào đó thì tiến hành hành vi động tác thứ hai so với câu mang bổ ngữ cảnh huống thời hạn có ý nghĩa biểu đạt tương đương trong tiếng Việt như sau:

Tiếng Hán: $\mathrm{S} / \mathrm{S} 1+\mathrm{V} 1+($ 完 $)+(\mathrm{O} 1)+\mathrm{C}$ (thời lượng $)+(\mathrm{S} 2)+($ 再/就 $)+\mathrm{V} 2+(\mathrm{O} 2)+$ (了).

Tiếng Việt: $\mathrm{S} / \mathrm{S} 1+\mathrm{V} 1+(\mathrm{C}$ (trực tiếp) / (gián tiếp $))+($ xong $) /($ xong $)+(\mathrm{C} 1$ (trực tiếp $) / \mathrm{C} 1$ (gián tiếp) $)+\mathrm{C}$ (cảnh huống thời hạn $)+(\mathrm{S} 2)$ + (rồi/thì/hãy/hẵng...) $+\mathrm{V} 2+(\mathrm{C} 2$ (trực tiếp) / C2 (gián tiếp)) .

Trước động từ thứ hai ở phân câu sau của tiếng Hán thường sử dụng các phó tù “就” hoặc “再” còn trước động từ thứ hai ở phân câu sau của tiếng Việt thường dùng các từ "rồi", "thì", "hãy"... tương đương với “就” hoặc “再” của tiếng Hán để biểu thị hành vi động tác thứ hai được thực hiện sau khi hành vi động tác thứ nhất bắt đầu hoặc hoàn thành cách một khoảng thời gian nhất định nào đó. Mô hình cấu trúc câu trong trường hợp này của tiếng Hán và tiếng Việt giống nhau khi trong câu không có tân ngữ. Khi trong câu có tân ngữ thì tiếng Hán vừa có cách sắp xếp giống vừa có cách sắp xếp khác với tiếng Việt.

Như vậy, có thể thấy mô hình kết cấu câu mang BNTL biểu thị hành vi động tác thứ hai được thực hiện sau khi hành vi động tác thứ nhất bắt đầu hoặc kết thúc cách một khoảng thời gian nhất định nào đó vừa có cách sắp xếp giống vừa có cách sắp xếp khác với cách biểu đạt tương đương trong tiếng Việt.

2.8. Đối chiếu mô hình kết cấu câu mang BNTL tiếng Hán khi động tì mang tân ngũ dài, phức tạp với tiếng Việt 
Tiếng Hán: $\mathrm{O}, \mathrm{S}+\mathrm{V}+($ 了 $)+\mathrm{C}$ (thời lượng) $+($ 了 $) / \mathrm{S}+\mathrm{V}+\mathrm{O}+\mathrm{V}+($ 了 $)+\mathrm{C}$ (thời lượng $+($ 了)

Tiếng Việt: C (trực tiếp) / (gián tiếp), $\mathrm{S}$ $+($ đã $)+\mathrm{V}+\mathrm{C}$ (cảnh huống chỉ thời hạn $)+$ (rồi) / S + V + C (trực tiếp) / (gián tiếp) $+\mathrm{C}$ (cảnh huống chỉ thời hạn) + (rồi)

Tác giả 李大忠 (1996) cho rằng: trường hợp câu mang BNTL và tân ngữ tương đối dài, phức tạp thì có thể đảo tân ngữ lên phía trước câu hoặc lặp lại động từ và tân ngữ đặt sau động từ thứ nhất trước bổ ngữ thời lượng. Tiếng Việt cũng có cách sắp xếp tương đồng với tiếng Hán là đặt bổ ngữ trực tiếp / bổ ngữ gián tiếp lên đầu câu, tuy nhiên tiếng Việt không có cách lặp lại động từ như tiếng Hán. Ví dụ:

（35）你借给我的那本中文小说, 我看 了十天才看完。/我看你借给我的那本中文 小说看了十天才看完。(《外国人学汉语 语法偏误分析》)

(Cuốn tiểu thuyết tiếng Trung mà bạn cho tôi mượn, tôi đã đọc mười ngày mới đọc xong. / Tôi đã đọc cuốn tiểu thuyết tiếng Trung mà bạn cho tôi mượn mười ngày mới đọc xong.)

Trên cơ sở đó, có thể thấy rằng mô hình kết cấu câu mang BNTL khi động từ mang tân ngữ dài, phức tạp trong tiếng Hán có cách sắp xếp giống và khác với tiếng Việt.

Sau quá trình phân tích và tổng hợp các kết quả nghiên cứu từ các dữ liệu của nhiều tác giả về phạm trù bổ ngữ thời lượng tiếng Hán, có thể thấy rằng các tác giả có thể xuất phát từ các góc độ khác nhau để đưa ra các kết luận về các mô hình kết cấu câu mang BNTL tiếng Hán. Tuy nhiên, dù là dựa vào tiêu chí: loại hình tân ngữ, loại động từ hay các ý nghĩa biểu đạt của bổ ngữ thời lượng thì các dạng thức, kết câu câu mang BNTL mà các tác giả đưa ra đều logic, thống nhất và có mối liên hệ chặt chẽ với nhau về vị trí của: động từ, tân ngữ, bổ ngữ thời lượng hay của các phó từ trong câu. Chúng tôi đã đi sâu vào phân tích một cách tương đối hoàn chỉnh các mô hình cấu trúc câu mang BNTL tiếng Hán và tiến hành đối chiếu với các cách biểu đạt tương đương trong tiếng Việt, đồng thời chỉ ra sự giống và khác nhau ở từng loại hình cấu trúc câu mang BNTL tiếng Hán và bổ ngữ cảnh huống chỉ thời hạn tiếng Việt.

\section{Kết luận}

Từ các kết quả phân tích và đối chiếu trên, chúng tôi cho rằng trật tự kết cấu câu mang bổ ngữ thời lượng tiếng Hán và mô hình cấu trúc câu có cách biểu đạt tương đương trong tiếng Việt vừa có sự tương đồng và vừa có sự khác biệt. Sự tương đồng được thể hiện ở mô hình kết cấu câu khi động từ không mang tân ngữ, khi động từ mang tân ngữ hữu định (tân ngữ là đại từ nhân xưng, tên người, hoặc có định ngữ cụ thể) và ở trật tự kết cấu câu khi động từ về mặt ý nghĩa không thể kéo dài hoặc duy trì lâu, bao gồm một số động từ ly hợp như: 毕业, 结婚, 起床, 开业, 离婚, 下 (课) ... hay các động từ như: 到, 来, 去, 死，离开... Trường hợp động từ trong câu là động từ li hợp biểu thị hành động duy trì hoặc kéo dài lâu là trường hợp mà mô hình cấu trúc câu mang bổ ngữ thời lượng tiếng Hán có sự khác biệt so với các cách biểu đạt tương đương của tiếng Việt. Các mô hình cấu trúc câu khi động từ mang tân ngữ tương đối dài, phức tạp, khi động từ mang tân ngữ vô định (tân ngữ là danh từ chỉ định tính thấp, chỉ chung chung, không xác định), mô hình kết cấu câu mang BNTL biểu thị hành vi động tác thứ hai được thực hiện sau khi hành vi động tác thứ nhất bắt đầu hoặc hoàn thành cách một khoảng thời gian nào đó và mô hình kết cấu câu mang BNTL có phó từ ở dạng khẳng định, phủ định là các trường hợp mà tiếng Hán vừa có cách sắp xếp tương đồng vừa có cách sắp xếp khác biệt so với tiếng Việt. 


\section{Tài liệu tham khảo}

\section{Tiếng Việt}

Diệp Quang Ban (2004). Ngũ pháp Việt Nam phần câu. Hà Nội: Nxb Đại học Sư phạm.

Diệp Quang Ban (2008). Giáo trình Ngũ pháp tiếng Việt, phần 2. Hà Nội: Nxb Giáo dục.

Diệp Quang Ban, Hồ Ngọc Trung (2010). Ngũ pháp Việt Nam, phần 2. Hà Nội: Nxb Giáo dục Việt Nam.

Phan Văn Các cùng nhóm tác giả (2006). Tù điển Trung Việt. Hà Nội: Nxb Khoa học xã hội

Cao Xuân Hạo (2003). Tiếng Việt - mấy vấn đề ngũ âm, ngũ pháp, ngũ nghĩa. Hà Nội: Nxb Giáo dục.

Nguyễn Văn Hiệp (2009). Cú pháp tiếng Việt. Hà Nội: Nxb Giáo dục.

Lưu Vân Lăng (2008). Nhũng vấn đề ngũ pháp tiếng Việt hiện đại. Hà Nội: Nxb Khoa học xã hội.

Trần Thị Thanh Liêm, Nguyễn Bích Hằng (2005). Ngũ pháp tiếng Hoa ( 中华的语法). Hà Nội: Nxb Văn hóa thông tin.

Nguyễn Thị Lương (2013). Bàn về viẹcc phân biệt trạng ngũ với một số thành phần khác trong câu tiếng Việt. Truy cập lúc 10:16 ngày 24/05/2017 tại http://nguvan.hnue.edu.vn/Nghiencuu/Ngonngu/ tabid/100/newstab/93/Default.aspx

Hoàng Phê (2003). Tù điển Tiếng Việt. Đà Nẵng: Nxb Đà Nẵng.

Hoàng Phê cùng nhóm tác giả (2014). Từ điển Tiếng Việt. Đà Nẵng : Nxb Đà Nẵng.

Nguyễn Kim Thản (1963). Nghiên cúu về ngũ pháp tiếng Việt tập 1. Hà Nội: Nxb Uỷ ban Khoa học xã hội.

Đào Minh Thu và nhóm tác giả (2005). Tập cú pháp tiếng Việt SP8.5 - Đề tài KC.01.01.05/06-10. Truy cập lúc 09:25 ngày 04/04/2017 tại http:// www.jaist.ac.jp/ bao/VLSP-text/Mar2009/SP85 baocaokythuat2009thang3.pdf

\section{Tiếng Trung Quốc}

陈小红 (2002). 《数量补语的用法和位置》, 暨南 大学华文学院学报

车慧, 张璐 (2016). 《韩国留学生习得汉语时量补 语的偏误分析及教学对策》, 辽宁医学院学报 ( 社会科学版）

储泽祥 (2005). 《肯定, 否定与时量成分在动词前 后的分析》, 汉语学报第四期

匡鹏飞 (2013). 《动词、时量成分与否定词的组合 形式及其语法特点》, 华中师范大学学报 (人文 社会科学版)

李大忠 (1996). 《外国人学汉语语法偏误分析》, 北京语言文化大学出版社

刘月华等著 (2001). 《实用现代汉语语法》- 增订 本, 商务印书馆
吕叔湘 (1992). 《通过对比研究语法》, 语言教学 与研究

莴晓伟 (2009). 《外国学生汉语数量补语习得研 究》, 中国学术期刊电子出版社

秦洪武 (2002). 《汉语 “动词+时量短语” 结构的情 状类型和界定分析》, 当代语言学-第二期第四 卷

谢静 (2010). 《英语国家留学生时量补语偏误分 析》, 硕士学位论文

孙德金 (2002). 《汉语语法教程》, 北京语言大学 出版社

间娇莲 (2007)。《时量补语与宾语共现时的分布与 原因探微》，职业卷

杨寄洲 (2006). 《汉语教程》第二册一上, 北京语 言大学出版社

杨峥琳, 刘倩 (2006)。《离合词中时量补语位置探 索- 从“结了十年婚” 说起》, 鞍山师范学院 学报

张雅冰 (2007). 《对外汉语教学时量补语的偏误分 析》, 辽宁教育行政学院学报

朱庆明 (2005). 《现代汉语实用语法分析》, 上册, 清华大学出版社

\section{Ngữ liệu chính}

Nam Cao (1941). Chí Phèo. Hà Nội: Nxb Đời mới.

Nam Cao (2002). Nhũng bàn tay đẹp ấy. Hà Nội: Nxb Văn học.

Nam Cao (2017). Sống mòn. Hà Nội: Nxb Văn học..

Hoàng Phê (1998). Tư điển Tiếng Việt. Hà Nội: Nxb Khoa học xã hội.

Nguyễn Quang Sáng (2014). Chiếc lược ngà. Tp. Hồ Chí Minh: Nxb Văn hóa - văn nghệ Tp Hồ Chí Minh.

北京大学中国语言学研究中心CCL语料库

蝶之灵(2009), 《奔跑的蜗牛》, 中国文联出版社

(Điệp Chi Linh (2009). "Ốc sên chạy". Nxb Liên văn Trung Quốc )

莫言(2009), 《哇》, 上海文艺出版社

(Mạc Ngôn (2009). "Éch". Nxb Văn nghệ Thượng Hải)

莫言( 2003), 《丰乳肥榍》, 中国工人出版社

(Mạc Ngôn (2003). "Báu vật của đời”. Nxb Công nhân Trung Quốc.)

九把刀(2007)《那些年我们一起追的女孩》, 花山文 艺出版社 (初版) 春天出版社

(Cửu Bả Đao (2007). "Cô gái chúng ta tùng theo đuổi năm nào”. Nxb Văn nghệ Hoa Sơn.) 


\title{
SENTENCE STRUCTURES WITH DURATION COMPLEMENTS IN CHINESE AND VIETNAMESE EQUIVALENTS
}

\author{
Nguyen Thi Huong \\ Department of Foreign Languages, Hung Yen University of Technology and Education, \\ 189 Nguyen Luong Bang, Tan Binh, Hai Duong, Vietnam
}

\begin{abstract}
A complement is one of the main components of the Chinese sentences. Chinese complements in general and duration complement in Chinese in particular have been used at a very high frequency. Within the framework of this paper, we focus on the order of sentence components with duration complements in Chinese and contrast them with the Vietnamese equivalents.
\end{abstract}

Keywords: duration complement, sentence structure, contrast, Vietnamese equivalents 